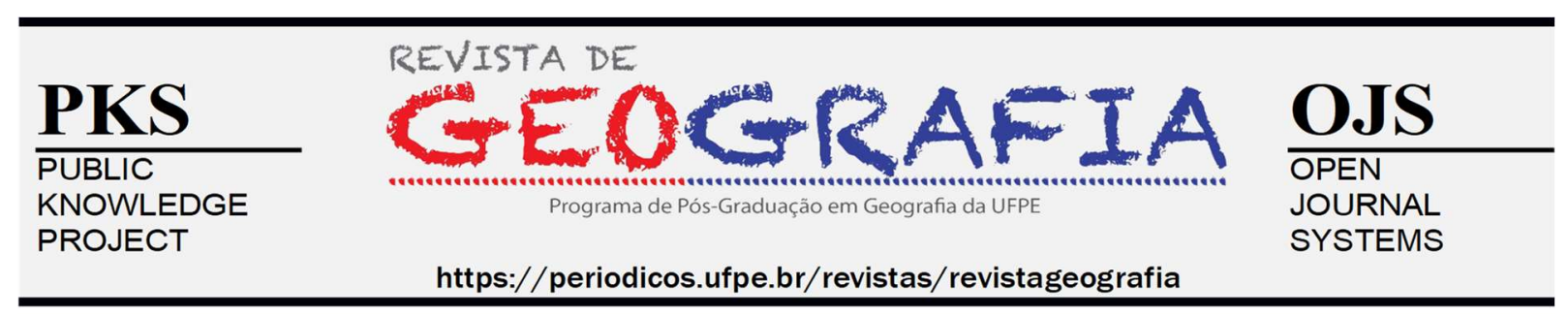

\title{
USO E COBERTURA DA TERRA E O PROCESSO DE DESERTIFICAÇÃO NO POLO REGIONAL DE JEREMOABO-BAHIA
}

\author{
Israel de Oliveira Junior ${ }^{1}$, Anderson de Jesus Pereira², Jocimara Souza Britto Lobão ${ }^{3}$, \\ Barbara-Christine Marie Nentwig Silva ${ }^{4}$
}

\begin{abstract}
${ }^{1}$ Geógrafo (Licenciatura em Bacharelado em Geografia), pela Universidade Estadual de Feira de Santana (UEFS); Mestre em Geografia, pela Universidade Federal da Bahia (UFBA); Doutor em Geografia, pela Universidade Federal da Bahia (UFBA).

${ }^{2}$ Graduação em Agronomia, pela Universidade Estadual de Feira de Santana (UEFS); Mestrando em Agronomia - Irrigação e Drenagem, pela Universidade Estadual Paulista (UNESP).

${ }^{3}$ Graduação em Geografia, pela Universidade Estadual de Feira de Santana (UEFS); Mestra em Geografia, pela Universidade Federal da Bahia (UFBA); Doutora em Geografia, pela Universidade Federal de Sergipe (UFS).

${ }^{4}$ Graduação em Geografia, pela Universität Freiburg (UNI FREIBURG) - Alemanha; Doutorado em Geografia, pela Universität Freiburg (UNI FREIBURG) - Alemanha.
\end{abstract}

Artigo recebido em 11/06/2020 e aceito em 31/07/2020

\begin{abstract}
RESUMO
No jogo de relações entre a sociedade e a natureza nas terras secas, a insustentabilidade ambiental das práticas, técnicas e tecnologias humanas configuram cenários de desertificação nas diferentes escalas espaciais, sejam locais, nacionais e regionais. Por meio desta pesquisa, analisou-se o uso e cobertura da terra como indicador ambiental de desertificação no Polo Regional de Jeremoabo, Estado da Bahia. Construiu-se o mapa de uso e cobertura da terra pela interpretação de imagens LANDSAT-8 associada aos dados de campo. Alguns testes foram realizados para a definição das classes dos mapas, de acordo com os dados de campo, resolução da imagem, escala cartográfica do mapa e referências sobre o tema. A agropecuária é um fator da supressão das feições vegetais em favor da ampliação dos campos de agricultura e de pecuária, que se estendem em mais de $15,4 \mathrm{mil} \mathrm{km}^{2}$, com indicativos de deterioração da vegetação e do ambiente, observáveis na (re)classificação das feições vegetais, a partir do qualitativo antropizada, para apontar a pressão na biodiversidade. Os níveis acentuados de degradação equivalem às classes Solo Exposto e Superfície Erosiva Flúvio-pluvial, resultantes da supressão da cobertura vegetal sobre os Neossolos, altamente suscetíveis aos processos erosivos.
\end{abstract}

Palavras-chave: Paisagem; Terras Secas; Degradação.

\section{USAGE AND COVERAGE OF LAND AND THE DESERTIFICATION PROCESS IN THE REGIONAL JEREMOABO-BA REGION}

\begin{abstract}
In the game of relationships between society and the nature in dry lands, environmental unsustainability of the human practices, techniques and technologies set up scenarios of desertification in different spatial scales, whether local, national and regional. Through this research soil use and coverage as an environmental indicator of desertification on Jeremoabo Regional Pole, State of Bahia, were analyzed. The soil use and coverage map was constructed from the interpretation of LANDSAT-8 images, associated with the field data. Some tests were conducted for the definition of the classes of maps, according to the data of field, image resolution, scale of map and cartographic references on the subject. Agriculture is a suppression factor of vegetation in favor of the expansion of agricultural and cattle raising fields, which extend over 15,400 square kilometers, with indications
\end{abstract}


of deterioration of vegetation and the environment, observable in the (re) classification of the vegetal features, with the anthropized qualitative, to point the pressure on the biodiversity. The high levels of degradation are equivalent to the classes of Exposed Soil and the Alluvial-fluvial Erosive Surface, resulting from the suppression of the vegetation cover on the Neosols, highly susceptible to erosive processes.

Keywords: Landscape; Drylands Degradation.

\section{INTRODUÇÃO}

A partir da década de 1970, a produção de estudos ambientais resultou em explicações complexas acerca da desertificação, explícitas, até mesmo, nos conceitos do processo (BRASIL, 2005; MAINGUET, 1995; NASCIMENTO, 2014; PACHÊCO et al., 2006; SUERTAGARAY, 2010). A análise desses indicou a ação humana como o fator primordial da degradação das terras secas, ao implicar no desequilíbrio ambiental, que retorna em impactos desfavoráveis à sociedade. A agropecuária, o extrativismo vegetal e mineral encontram-se entre as principais atividades de tensão ambiental propagadoras, em todo o mundo, da desertificação, inclusive no Brasil (BRASIL, 2005). A busca de resultados imediatos do trabalho, na produção de mercadorias para distintas metas, aponta para a relação contraditória humana com os demais componentes ambientais, por gerar e ampliar os graus e escalas espaciais da degradação ambiental - que também é a degradação da vida humana e da sociedade - e corroborar com o estado de crise ambiental planetária.

Imensas áreas encontram-se propensas à ocorrência da desertificação em todo o mundo, devido à exploração social diante de um ambiente frágil devido às condições climáticas e pedológicas (UNITED NATIONS, 1994). No Brasil, a Área Susceptível à Desertificação (ASD) engloba espaços de onze estados, distribuídas em 15,7\% do território nacional (BRASIL, 2005). O Estado da Bahia possui 289 municípios na ASD, em um total de $490 \mathrm{mil} \mathrm{km²}$, equivalente a $86,8 \%$ das terras estaduais (BAHIA, 2014). Desde a década de 1970, houve esforços para abordar sobre a desertificação, com a indicação de núcleos pontuais importantes de ocorrência do processo, no norte e no nordeste do estado (AB'SABER, 1977; VASCONCELOS SOBRINHO, 1971). No entanto, as marcas da incipiência das pesquisas sobre o tema esbarram na publicação tardia do Plano Estadual de Combate à Desertificação e Mitigação dos Efeitos da Seca (PAE-BA) em 2014 (BAHIA, 2014).

No ano de 2009, definiu-se 52 municípios para o diagnóstico ambiental e implementação do PAE-BA, regionalizados em quatro polos (LOBÃO; VALE, 2013), nomeados como polos regionais de Guanambi, Irecê, Jeremoabo e Juazeiro, constituídos por tais municípios e outros circunvizinhos. A partir das regionalizações elaboradas no âmbito das atividades do PAE-BA e da degradação ambiental indicadas em trabalhos anteriores 
(AB'SABER, 1977; LOBÃO; SILVA, 2013; LOBÃO; VALE, 2013; OLIVEIRA JUNIOR et al. 2018; VASCONCELOS SOBRINHO, 1971), definiu-se o Polo Regional de Jeremoabo como a área de estudo para esta pesquisa.

Os estudos científicos apontam para a existência de núcleos em estágios avançados da degradação ambiental, iniciados pela supressão das feições vegetais sobre os solos com superfícies arenosas (AB'SABER, 1977; BRASIL, 2005; VASCONCELOS SOBRINHO, 1971, 2002). São retratos da incoerência produtiva, porque as ações humanas, sem os cuidados técnicos apropriados para o trópico semiárido, incorrem em processos de degradação e propiciam a desertificação, corroborando para o ressecamento pedológico e a perda da capacidade de produção dos solos (HARE et al., 1992; NIMER, 1988).

O Polo Regional de Jeremoabo caracteriza-se pela reduzida e concentrada pluviosidade, além da ocorrência de secas intervalares. Nesses cenários, a sociedade se reproduz, utiliza, domina, preserva, conserva e consome o patrimônio do meio; produz, submete, sujeita-se, contrapõe às políticas; causa, lucra e padece dos efeitos da má utilização do ambiente. Esses processos são evidenciados para instalar ou intensificar a vulnerabilidade ambiental, que apontam para o efeito de uma crise ambiental planetária.

$\mathrm{O}$ uso e cobertura da terra é um indicador que revela o estado ambiental e denota fatores (força motriz e pressão) e efeitos (impactos e respostas) de vulnerabilidade mediante à apropriação humana do patrimônio ambiental. Assim, por meio deste estudo, objetivou-se analisar o uso e cobertura da terra como indicador de desertificação no Polo Regional de Jeremoabo, Estado da Bahia. Para tanto, realizou-se o mapeamento a partir da interpretação de imagens de satélite associada aos dados levantados em estudos de campo.

\section{ÁREA DE ESTUDO}

O Polo Regional de Jeremoabo compõe a ASD brasileira, possui uma extensão de 25 mil km², é composto por 13 municípios localizados no norte da Bahia (Figura 1). A área é dominada pelo clima tropical semiárido (SUPERINTENDÊNCIA DE ESTUDOS ECONÔMICOS E SOCIAIS DA BAHIA, 1999), por rios intermitentes, excetuando o Rio São Francisco e o baixo e o médio curso do Rio Vaza-Barris. As feições vegetais são específicas do bioma Caatinga, e a maior parte dos municípios possui uma economia baseada na agropecuária, que está fortemente ligada ao processo de desertificação em muitos núcleos brasileiros (BRASIL, 2005; SALES, 2002, 2003; SOUZA et al., 2009). Na região, localiza-se a área de 
proteção ambiental (APA) Serra Branca/Raso da Catarina e a reserva ecológica Raso da Catarina, delimitada com o intuito de conservar o ambiente e realizar pesquisas científicas (PAES; DIAS, 2008).
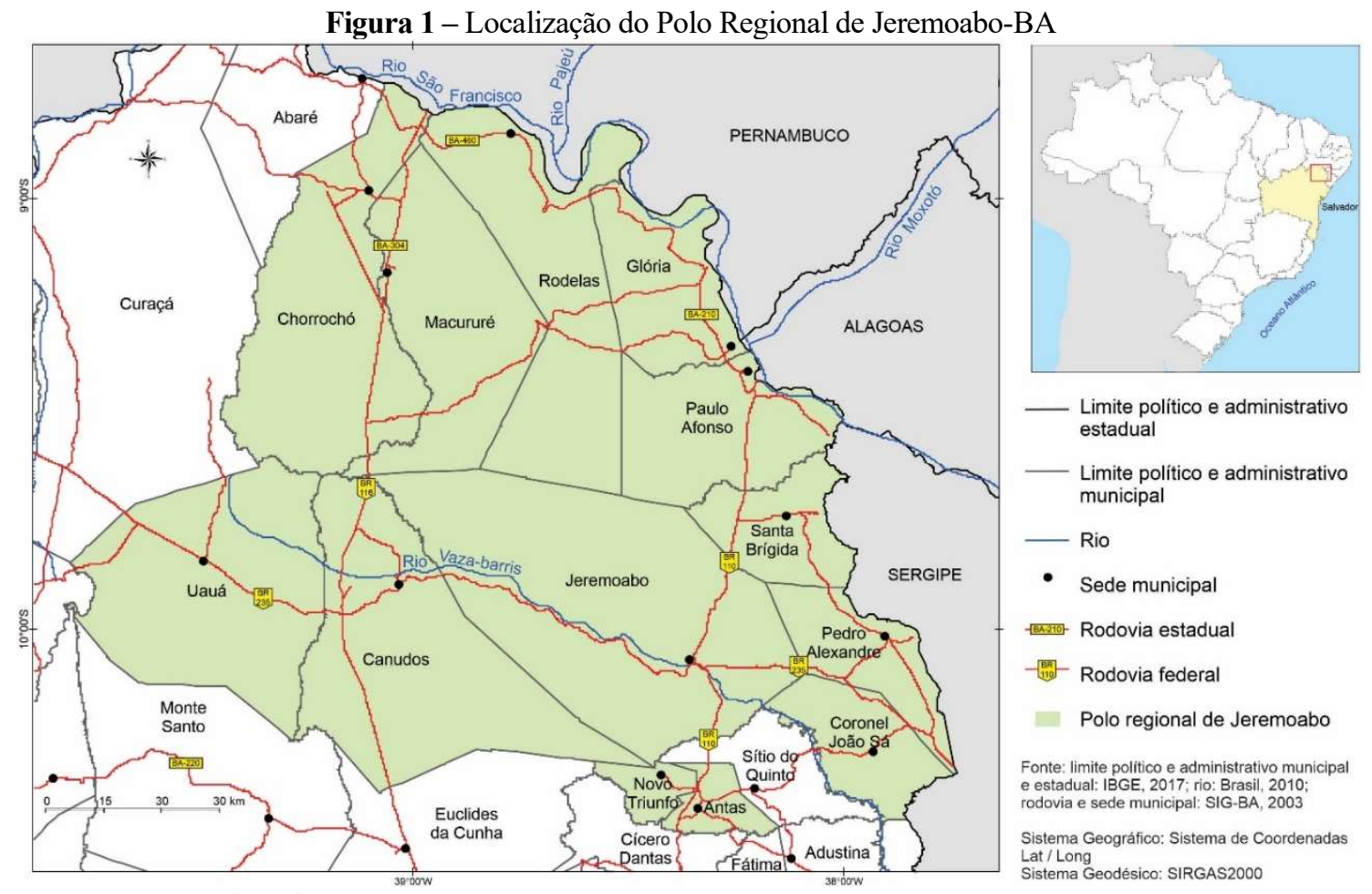

Fonte: Autores (2020)

A quantidade populacional do Polo Regional de Jeremoabo, em 2010, foi de 309.004 habitantes, representou $2,1 \%$ da população total do Estado da Bahia e distribuiu-se distintamente entre os municípios regionais. Paulo Afonso possuiu a maior população do polo (cerca de 108,4 mil pessoas), seguido por Jeremoabo, o segundo mais populoso, com 37.680 habitantes. Os demais municípios tiveram uma população inferior a 25 mil habitantes. A taxa da população rural é superior a 50\% na maioria dos municípios, denotando a importância das atividades agropastoris para a sociedade local.

\section{MATERIAIS E MÉTODO}

A utilização dos produtos de sensoriamento remoto nos estudos ambientais possibilitou uma análise dinâmica das feições paisagísticas em diversas escalas espaciais e temporais. Novas técnicas foram introduzidas para o mapeamento de uso e cobertura da terra, com o intuito de identificar os padrões e formas dos objetos geográficos em imagens de satélites. A diversidade de trabalhos com o emprego do sensoriamento remoto denotou o 
potencial das imagens ópticas nos estudos ambientais (AJAJ et al., 2017; ANDRADE; OLIVEIRA, 2004; AQUINO et al., 2012; CHEN et al., 2006; DRONOVA et al., 2012; ESTOQUE; MURAYAMA, 2015; PONZONI, 2009; RIBEIRO; ALBUQUERQUE, 2017; RUDORFF et al., 2007). Procedeu-se, com isso, uma riqueza de métodos de mapeamento de uso e cobertura da terra, com diversas aplicações e resultados.

Para a construção do mapa de uso e cobertura da terra, empregou-se imagens do sensor LANDSAT-8 (Figura 2), compostas por sete bandas, definidas em intervalos do espectro eletromagnético. Os procedimentos para a realização do mapeamento dividiram-se em duas fases: i) pré-processamento; ii) processamento digital de imagens, subsidiados pelos levantamentos de dados e informações em campo (Figura 2). As imagens do sensor LANDSAT8 recobriram toda a área de estudo e foram selecionadas considerando a disponibilidade em virtude da baixa cobertura de nuvens.

Figura 2 - Síntese dos procedimentos metodológicos empregados na construção do mapa de uso e cobertura da terra

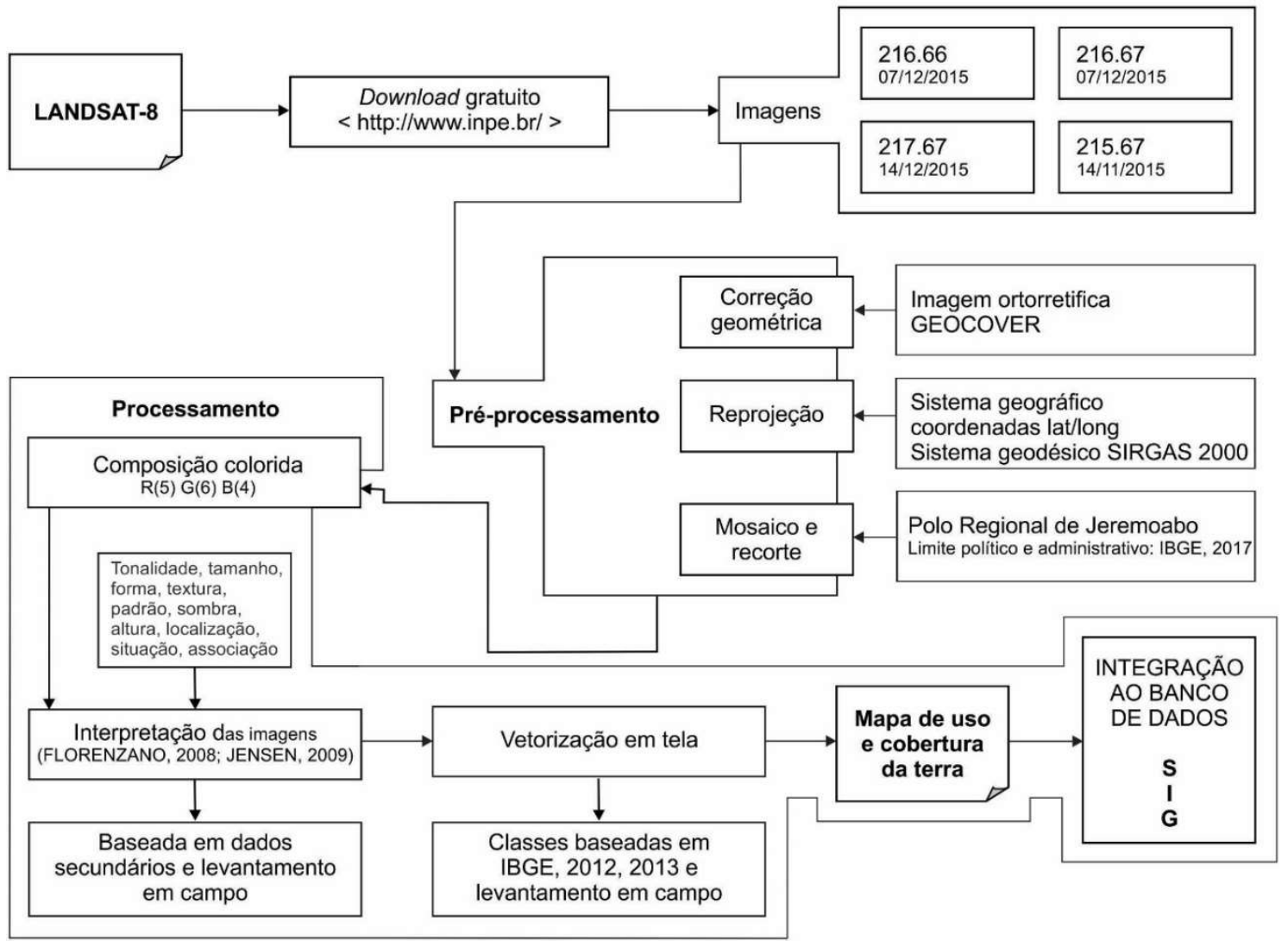

Fonte: Autores (2020)

$\mathrm{Na}$ etapa do pré-processamento das bandas utilizadas para o mapeamento, corrigiu-se os erros geométricos, baseado em outras cenas ortorretificadas; alterou-se o sistema geográfico 
(sistema de coordenadas geográficas) e o sistema geodésico (SIRGAS2000); construiu-se o mosaico das cenas que recobriam a área de estudo e o recortou de acordo com o perímetro do Polo Regional de Jeremoabo (Figura 2). Em função de não proceder com as técnicas estatísticas de interpretação das imagens, excluiu-se a correção atmosférica e radiométrica.

Iniciou-se a fase do processamento com os testes de composição colorida das bandas do sensor LANDSAT-8 pré-processadas, definida em razão da distinção dos alvos imageados interessantes para o mapeamento, como as feições vegetais (Figura 2). A interpretação das imagens subsidiou a construção de uma chave de interpretação e a vetorização em tela das classes dos mapas.

Depois da interpretação preliminar dos padrões das imagens, realizou-se um levantamento de informações em campo para relacionar as características das imagens com as particularidades ambientais do polo e verificar a chave de interpretação. Nos estudos de campo, preencheu-se fichas com os dados e informações obtidas pela avaliação das características da cobertura da terra e os correspondentes usos, cujos resultados integraram o SIG da pesquisa. Os levantamentos de campo sobressaíram entre os dados e informações referentes ao uso e cobertura da terra, pois foram associados aos padrões do mosaico, o que possibilitou mapear as classes não distinguíveis nos produtos de sensoriamento remoto. Assim, a reconstrução da chave de interpretação, relacionada aos dados de campo, tornou-se mais consistente e contribuiu para o mapeamento mais coerente com a realidade da terra.

\section{RESULTADOS E DISCUSSÃO}

A nomenclatura do uso e cobertura da terra ajustou-se ao mapeamento dos principais usos e coberturas existentes de forma precisa e perceptíveis nas imagens LANDSAT-8, na tentativa de exaurir dúvidas de interpretação e fundamentais para estabelecer a vulnerabilidade ambiental. No esquema teórico das classes, identificou-se as atividades econômicas realizadas e os resultantes objetos que cobrem as superfícies, cujas informações são importantes para analisar o estado ambiental no Polo Regional de Jeremoabo (Quadro 1).

Para determinadas classes, ajustou-se as terminologias, devido às obras analisadas não contemplarem informações de objetos regionais. As adequações referiram-se às feições vegetais da caatinga, as quais, nas obras (IBGE, 1992, 2012), denominaram-se de savanas estépicas e as características descritas não assemelharam às da cobertura vegetal. Nos textos (IBGE, 1992, 2012), observou-se, pois, o menor detalhamento das classificações inerentes ao 
bioma caatinga, que reafirma a escassez de estudos ambientais específicos sobre o trópico semiárido brasileiro e a exiguidade de dados e de indicadores ambientais importantes para o planejamento e políticas eficazes.

Quadro 1 - Definição das classes de uso e cobertura do Polo Regional de Jeremoabo-BA

\begin{tabular}{|c|c|}
\hline Classe & Definição \\
\hline $\begin{array}{l}\text { Caatinga arbóreo- } \\
\text { arbustiva }\end{array}$ & $\begin{array}{l}\text { Estrutura-se, fundamentalmente, em dois estratos lenhosos, de densidade contínua e } \\
\text { semicontínua: um superior, com porte, em média, de } 5 \mathrm{~m} \text {; e um estrato inferior, arbustivo, } \\
\text { com espécies de até } 3 \mathrm{~m} \text { de altura. Caracteriza-se por uma composição de espécies } \\
\text { decíduas, espinhentas, com microfolia e heterogeneidade florística }\end{array}$ \\
\hline $\begin{array}{l}\text { Caatinga arbóreo- } \\
\text { arbustiva } \\
\text { antropizada }\end{array}$ & $\begin{array}{l}\text { Encontram-se dois estratos lenhosos: arbóreo e arbustivo, com características } \\
\text { semelhantes ao da caatinga arbóreo-arbustiva. A pecuária reduziu a densidade da } \\
\text { vegetação, que, em alguns locais, é secundária, possui acentuada homogeneidade e/ou } \\
\text { propagação de espécies }\end{array}$ \\
\hline Caatinga parque & $\begin{array}{l}\text { Formada por dois estratos: i) um superior arbustivo, com espaçamento dos indivíduos } \\
\text { (como se fossem plantados), lenhosos e espinhosos, decíduos e semidecíduos e } \\
\text { microfoliados; ii) um inferior, com predomínio de gramíneas regionalmente denominada } \\
\text { de capim-panasco (Aristida sp.), que recobrem densamente o solo no período chuvoso }\end{array}$ \\
\hline $\begin{array}{l}\text { Caatinga parque } \\
\text { antropizada }\end{array}$ & $\begin{array}{l}\text { Características idênticas à caatinga parque, em relação à composição dos estratos e } \\
\text { espécies. A pecuária acentuou o espaçamento, diminuiu a densidade e ritmo de } \\
\text { recomposição das gramíneas, propagou espécies ruderais de porte herbáceo }\end{array}$ \\
\hline Campo ru & $\begin{array}{l}\text { Encontra-se nas encostas e topos de relevos residuais e serras de topografia acidentada, } \\
\text { formadas por solos rasos, como os Neossolos, e afloramentos rochosos. Ocupa trechos } \\
\text { descontínuos, constitui mosaicos, onde predominam os estratos graminoides, integrados } \\
\text { por hemicriptóficos, geófitos e musgos (período chuvoso). Nas diáclases e fraturas das } \\
\text { rochas, onde a águam penetra e há solo, medram, isoladamente, espécies vegetais } \\
\text { arbustivos e subarbustivos, que se misturam em fisionomias das caatingas e cerrados }\end{array}$ \\
\hline Cidade & $\begin{array}{l}\text { ralmente, corresponde à sede do município, onde situa-se a prefeitura municipal, com } \\
\text { ensamento populacional, predomínio de objetos urbanos (vias de transporte, } \\
\text { municação etc.) e atividades comerciais e de serviços }\end{array}$ \\
\hline Lago & $\begin{array}{l}\text { para o } \\
\text { ergia }\end{array}$ \\
\hline Lavoura irrigada & $\begin{array}{l}\text { e irrigação, para a produção de alimentos, } \\
\text { ão }\end{array}$ \\
\hline Past & ncluem- \\
\hline Rio & $\begin{array}{l}\text { água natural, com volumes de água inconstantes. Os rios intermitentes são } \\
\text { ente dependentes do ritmo climático sazonal e os perenes ocorrem apenas nas } \\
\text { de fontes alóctones }\end{array}$ \\
\hline posto & $\begin{array}{l}\text { perfícies desnudas, que representam as terras onde o uso sistemático tem diminuído o } \\
\text { no da recomposição florística }\end{array}$ \\
\hline $\begin{array}{l}\text { Lavoura e pastagem } \\
\text { alternadas }\end{array}$ & $\begin{array}{l}\text { Ocorrência combinada entre lavoura e pastagem. Há o estabelecimento dos cultivos no } \\
\text { período chuvoso, interrompendo-se a partir das estiagens pluviométricas, com a } \\
\text { formação imediata das pastagens }\end{array}$ \\
\hline $\begin{array}{l}\text { Superfície erosiva } \\
\text { flúvio-pluvial }\end{array}$ & $\begin{array}{l}\text { argens dos rios e pequenos córregos intermitentes, onde a vegetação original foi } \\
\text { primida, sucedem processos erosivos acelerados e estados de deterioração ambiental }\end{array}$ \\
\hline $\begin{array}{l}\text { Vegetação com } \\
\text { influência lacustre e } \\
\text { fluvial }\end{array}$ & $\begin{array}{l}\text { Medra sobre planícies aluviais sujeitas às cheias dos rios, ou nas depressões alagáveis. } \\
\text { De acordo com a umidade, as espécies podem apresentar-se mais vigorosas, com estratos } \\
\text { arbóreos ou menos desenvolvidos (estratos arbustivos e herbáceos) }\end{array}$ \\
\hline Vila & $\begin{array}{l}\text { Pequena aglomeração urbana, com adensamento populacional inferior às cidades. } \\
\text { Embora incluída na categoria urbana, a população residente possui vínculos com } \\
\text { atividades rurais }\end{array}$ \\
\hline
\end{tabular}

Fonte: IBGE (1992, 2006, 2012, 2013) - adaptado.

Organização: Autores (2020) 
Nas imagens LANDSAT-8 selecionadas para o mapeamento, identificou-se o erro geométrico e temporal, este ocasionado pelas datas distintas de imageamento. Analisou-se, cuidadosamente, as imagens para a construção de uma chave de interpretação, que definiu as características dos alvos relacionadas às classes de uso e cobertura (Figura 3).

Figura 3 - Chave de interpretação das imagens LANDSAT-8 relacionada às classes de uso e cobertura da terra do Polo Regional de Jeremoabo-BA - composição colorida 5 (R), 6 (G), 4 (B)

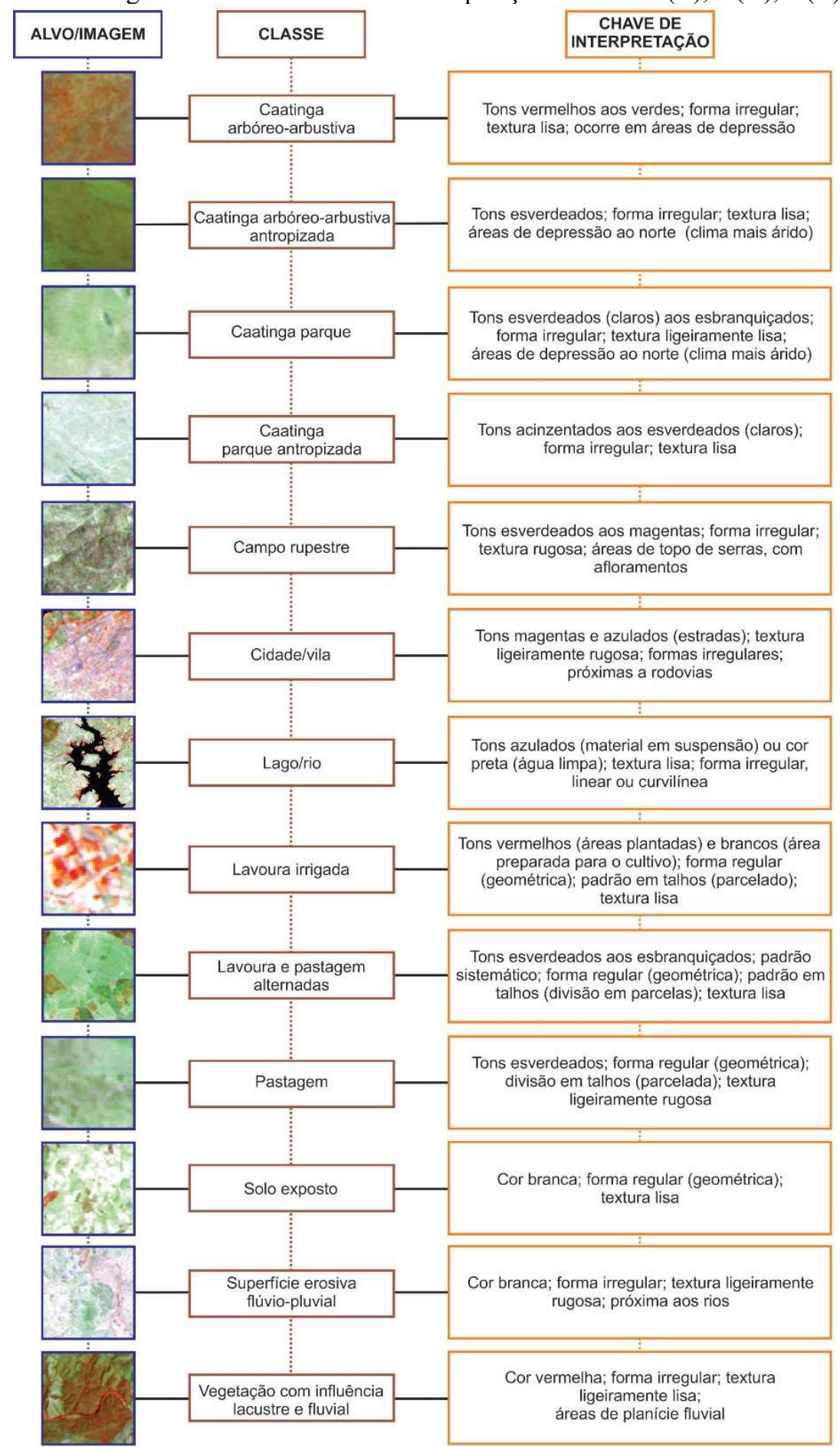

Fonte: Autores (2020) 
No processo de mapeamento, buscou-se dados para a distinção das classes das feições vegetais regionais em função das escalas geográfica (regional) e cartográfica, bem como ao objetivo de estudo. Assim, as classificações e terminologias consideraram a influência climática e edáfica nas feições vegetais, refletidas nos extratos e densidade delas, que compõem um conjunto de dados relevantes para avaliação da vulnerabilidade ambiental, observável em levantamentos de dados em campo. Por meio da análise de imagens de satélites, foi possível diferenciar as estruturas (porte e densidade) das feições vegetais e classificá-las em virtude do comportamento espectral dos alvos.

Após testes, a composição colorida mais adequada para o mapeamento agregou as bandas 5, 6 e 4, integradas, respectivamente, aos canais vermelho (R), verde (G) e azul (B). Por intermédio dela, percebeu-se as diferentes classes, sobretudo, das feições vegetais da caatinga, as quais são difíceis de separar por assemelharem-se no vigor da biomassa verde em determinados períodos anuais, em função da sazonalidade climática e das espécies.

A partir da aplicação da chave de interpretação (Figura 3), dados de campo, análises das imagens LANDSAT-8, associados às fontes secundárias, produziu-se o mapa de uso e cobertura da terra em escala cartográfica de 1/60.000 (Figura 4). A superfície recoberta por vegetação destaca-se na paisagem regional, onde se distribui em mais de 16,8 mil km² (Tabela 1) e ocupa, sobretudo, os relevos depressivos e o Raso da Catarina. Nessas áreas, o clima é mais seco, o déficit hídrico é mais acentuado e há dificuldades de realizar o uso pela agropecuária; por isso, inclusive, as feições vegetais encontram-se conservadas ou preservadas.

A caatinga arbóreo-arbustiva (Figura 5) recobre acima de 40\% da área de estudo. No oeste e no centro da região, o processo de uso e ocupação não tem se apropriado intensamente das terras, o que proporcionou uma contiguidade espacial da vegetação. Ao contrário do que ocorreu no leste, onde o uso da terra fragmentou a caatinga arbóreo-arbustiva constituída por pequenas manchas (Figura 4).

A caatinga arbóreo-arbustiva antropizada (Figura 5) refere-se à feição vegetal sem primitividade, ou seja, com modificações humanas na densidade, espécies e porte da vegetação (Quadro 1). Os impactos causados estão relacionados às atividades pecuaristas, a partir da criação extensiva do gado bovino, caprino e ovino, pois são abertas clareiras para o gado caminhar em meio às caatingas; os animais consomem as leguminosas e há dificuldades na germinação e desenvolvimento de plantas nativas em razão do sobrepastoreio e/ou pisoteio (compactação dos solos). A caatinga arbóreo-arbustiva antropizada encontra-se fragmentada e 
cobre $4 \%$ das terras do polo, o que equivale a cerca de $1.000 \mathrm{~km}^{2}$, sobremaneira, nas áreas onde há maior umidade e correm rios intermitentes no período chuvoso, pois existem condições para um uso mais intenso (Figura 4).

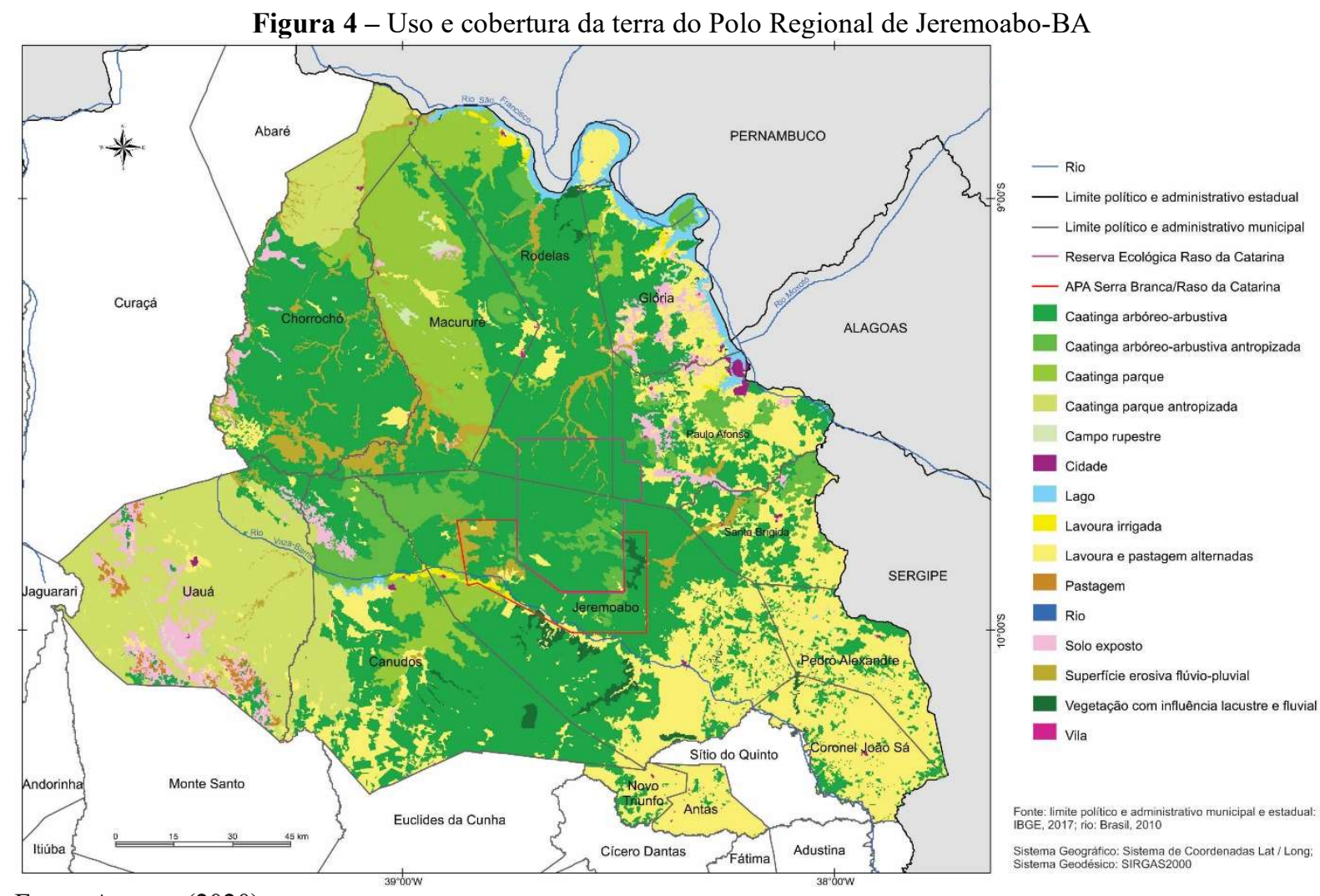

Fonte: Autores (2020)

Tabela 1 - Extensão das classes do mapa de uso e cobertura da terra do Polo Regional de Jeremoabo-BA - $\mathrm{km}^{2}$

\begin{tabular}{lr}
\hline Classe & Extensão \\
\hline Caatinga arbórea-arbustiva & $10.364,310$ \\
Caatinga arbórea-arbustiva antropizada & $1.007,660$ \\
Caatinga parque & $2.082,588$ \\
Caatinga parque antropizada & $2.854,368$ \\
Campo rupestre & 98,412 \\
Cidade & 50,890 \\
Lago & 380,985 \\
Lavoura e pastagens alternadas & $5.568,293$ \\
Lavoura irrigada & 156,010 \\
Pastagem & 91,692 \\
Rio & 3,365 \\
Solo exposto & 846,456 \\
Superfície erosiva flúvio-pluvial & $1.171,436$ \\
Vegetação com influência lacustre e fluvial & 283,922 \\
Vila & 21,012 \\
\hline Fonte: Autores (2020) &
\end{tabular}


Figura 5 - Características ambientais e classes de uso e cobertura das terras - Polo Regional de Jeremoabo-BA

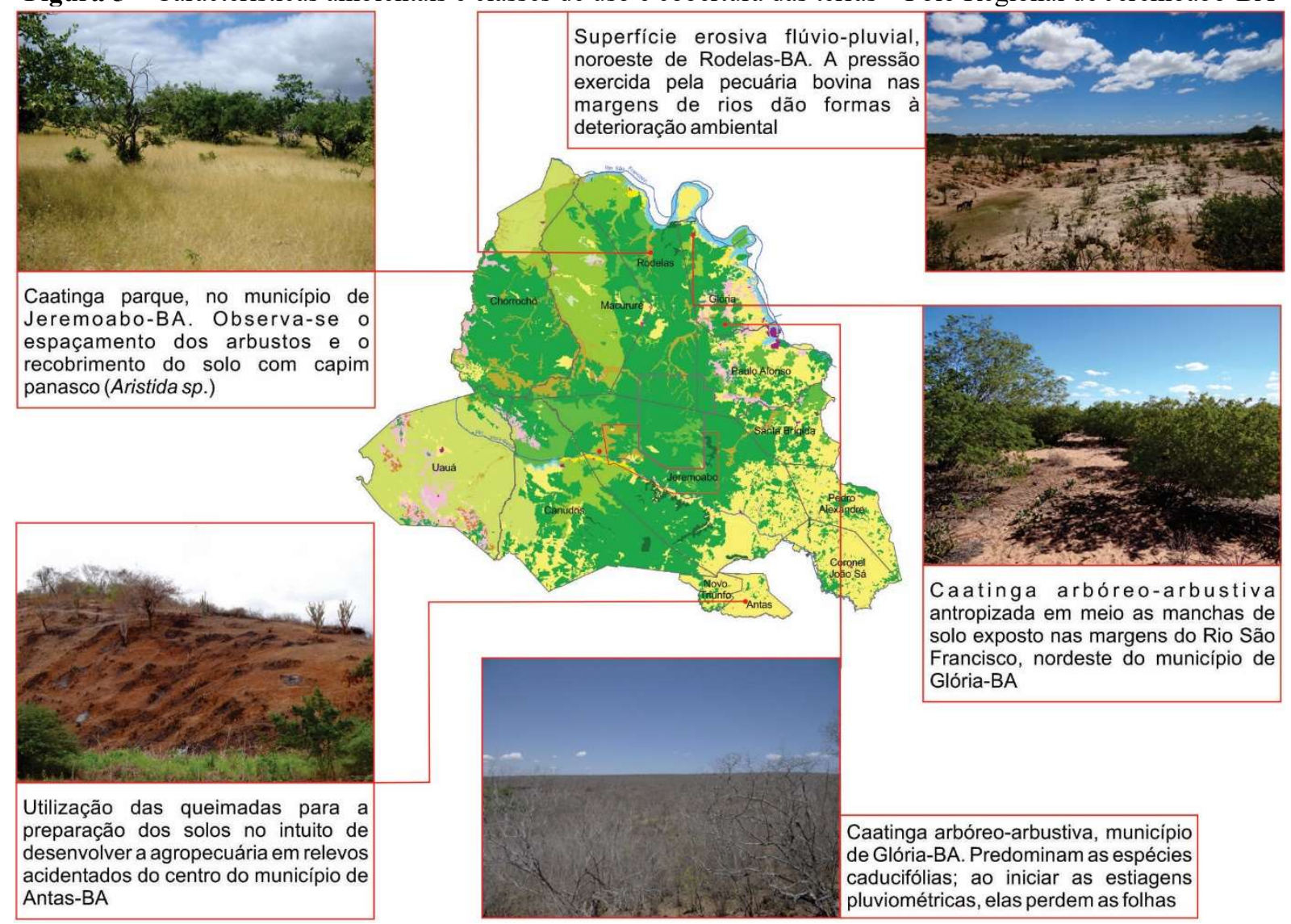

Fonte: Autores (2020)

A caatinga parque medra nas áreas onde a pluviosidade é mais escassa e ocorrem climas mais secos. Ela reveste $8 \%$ das terras do polo, em uma extensão de 2,08 mil km² (Tabela 1). A antropização da referida feição vegetal provocou mudanças no padrão da biomassa (densidade, espécies e porte) e determinou a definição da classe caatinga parque antropizada, que recobre $2.854 \mathrm{~km}^{2}$, um total de $11,4 \%$ da região. Nas terras revestidas por essa classe, o gado é criado solto no meio da vegetação, alimenta-se de determinadas espécies vegetais, como o capim-panasco (Aristida sp.), acentuou o espaçamento dos arbustos, tornou diminutivos a densidade e o ritmo de recomposição das gramíneas, propagou as espécies pioneiras de porte herbáceo e ampliou a áreas de solos expostos, constituindo forças motrizes e pressão para desencadear um estado de degradação ambiental e maior vulnerabilidade à desertificação desses ambientes.

O campo rupestre cresce nas encostas e topos dos relevos residuais de topografia acidentada, em meio aos afloramentos rochosos. Constitui $98,4 \mathrm{~km}^{2}$ do polo $(0,4 \%$ da área total $)$ e compõe pequenas manchas distribuídas espaçadamente nas paisagens regionais (Figura 4 e Tabela 1). 
Embora seja destacável a presença de rios perenes, como o São Francisco e VazaBarris, e algumas dezenas de rios intermitentes e efêmeros, com a ocorrência do fenômeno da inundação das áreas ribeirinhas no período das chuvas, existe pouca vegetação com influência lacustre e fluvial. As terras revestidas por esta classe somam $283,9 \mathrm{~km}^{2}$, cerca de $1 \%$ da área de estudo (Figura 4 e Tabela 1). Nas margens do curso do Rio São Francisco na região, por exemplo, a ocorrência de atividades agropastoris desmatou a vegetação natural e, hoje, inexiste, praticamente, a mata ciliar.

Isso tem ocasionado mudanças abruptas no ambiente, a ponto de definir uma classe específica para determinadas áreas de margens de rios, denominada superfície erosiva flúviopluvial (Figuras 4 e 5). Nessa, há evidências de um estado de desequilíbrio ambiental em virtude dos processos erosivos acentuados, que demarcam as paisagens e as tornam intensamente vulneráveis à desertificação. São ambientes formados por Neossolos, altamente friáveis e com granulometria arenosa, onde os processos erosivos em sulcos progridem para a formação e alastramento de ravinas, além de bancos de areia nos leitos dos rios. Nas margens desses, as poucas espécies de vegetação existentes têm as suas raízes expostas e, nos relevos com declividade, são comuns tombarem, por causa da força das águas fluviais no período das chuvas torrenciais, que removem os sedimentos e as desprendem dos solos. As áreas mapeadas com essa classe totalizaram $1.171,4 \mathrm{~km}^{2}$, o que representa $4,7 \%$ do polo (Tabela 1 ); nelas se criam extensivamente o gado bovino, caprino e ovino, porque, no período chuvoso, encontram-se espécies vegetais herbáceas com maior abundância para a dieta animal.

As superfícies antropizadas onde são desenvolvidas atividades agropecuárias possuem uma extensão de 7.677,2 km², cerca de $30 \%$ do Polo Regional, e é resultante de atividades relacionadas à pecuária e/ou à agricultura. Os usos têm fragmentado, acentuadamente, as feições vegetais das margens dos rios intermitentes, São Francisco, Vaza-Barris, e das terras no leste da região, constituindo forças motrizes para intensificar a vulnerabilidade ambiental à desertificação do polo (Figura 4). A agricultura irrigada ocorre, principalmente, nas margens do Rio Vaza-Barris e do Rio São Francisco, e recobre as terras com lavouras irrigadas temporárias e perenes em uma extensão de $156 \mathrm{~km}^{2}$, ou seja, $0,6 \%$ da área de estudo. Através da técnica de irrigação, são produzidas, especialmente, frutíferas (banana, coco, manga, melancia e melão) para o comércio e consumo locais e regionais. Pela pequena dimensão de terras onde reproduzem o uso agrícola com técnicas de irrigação, sobressai a dependência das 
atividades agropastoris à pluviosidade, que pode falhar por meses em determinados anos e desencadear e/ou ampliar a vulnerabilidade ambiental.

A pecuária extensiva ocorre em $5.981,6 \mathrm{~km}^{2}$ e condiciona a formação de distintas paisagens, como as de pastagem, solo exposto e superfície erosiva flúvio-pluvial (Figura 4 e Tabela 1), que dão forma a um estado de desequilíbrio. Na região, historicamente, parte da economia reproduz-se por meio da criação do gado bovino, caprino e ovino; ela está atrelada, também, aos processos de degradação, devido à inexistência da aplicação generalizada de manejos sustentáveis para ambientes do trópico semiárido. A pastagem recobre $91,7 \mathrm{~km}^{2}$ $(0,4 \%)$, constitui-se de pequenas manchas e tem ocasionado a remoção da vegetação nativa e a propagação de espécies pioneiras (Figura 4).

As áreas de solo exposto são mais visíveis em virtude da extensão $\left(846,5 \mathrm{~km}^{2} ; 3,4 \%\right.$ da região) e distribuição; configuram os ambientes de alta vulnerabilidade ao processo de desertificação (Figura 4 e Tabela 5) por revelar um estado ambiental crítico. Isso se deve à incidência e potência de processos erosivos laminares e acelerados, que carregam os nutrientes e os sedimentos mais finos dos solos e tornam difícil a reprodução de espécies vegetais e de cultivos. Ademais, a regeneração da vegetação dos ambientes semiáridos é naturalmente difícil e lenta, por causa das condições climáticas, dispersão das sementes e estrutura dos solos (MIRANDA et al., 2004), o que demarca a baixa elasticidade ambiental.

A agropecuária indica a reprodução alternada da agricultura e pecuária e dá gênese às terras revestidas ora de lavoura, ora de pastagem, em uma dinâmica sazonal. O início dessa atividade econômica na região remonta ao século XVII, quando a sociedade, na época, sobrevivia e/ou se enriquecia pelo uso combinado da lavoura e pastagem, em razão da ciclicidade das chuvas e estiagens, o que ainda é muito comum nos diais atuais. Esse fato é evidenciado na extensão da classe de lavoura e pastagem alternadas, que recobre $5.568,3 \mathrm{~km}^{2}$, representa $22,3 \%$ das terras e distribui-se por toda a região, sobretudo no leste e no sudeste, nas áreas próximas aos rios, onde há uma maior oferta de água no sistema ambiental (Figura 4 e Tabela 1).

As áreas urbanizadas correspondem a $71,9 \mathrm{~km}^{2}$ e subdividem-se em vilas e cidades regionais, as quais representam, em ordem, 0,2\% e 0,08\% do polo. Esses dados indicam que grandes somas de terras não são apropriadas no processo de urbanização. No mapa, a mancha urbana mais evidente corresponde à cidade de Paulo Afonso (Figura 4). 
A superfície aquática é composta por rio e lago, cujas águas recobrem $384,5 \mathrm{~km}^{2}$ do polo e são utilizadas para diferentes fins, como abastecimento humano e animal, lazer, irrigação e geração de energia. Há uma inconstância no volume de água dos rios e lagos em função da sazonalidade climática e da alta taxa de evaporação. A maior quantidade da drenagem é intermitente, efêmera e o fluxo de água é irregular, porque está associado à ocorrência das precipitações pluviométricas que podem faltar por meses e, em casos severos de secas, por anos.

Em alguns municípios, a pressão exercida pelo uso das terras regionais apoderou-se do patrimônio ambiental e reduziu as áreas recobertas por vegetação (Figura 4). Logo, evidenciam-se, nessas terras, perdas da biodiversidade animal e vegetal, fragmentação das paisagens, exposição dos solos às intempéries, condicionantes de uma situação preocupante, por conjugarem-se para um estado de degradação. Perde-se, com isso, o conhecimento sobre as riquezas ambientais, pelos ínfimos estudos e pesquisas locais (CONSELHO NACIONAL DA RESERVA DA BIOSFERA DA CAATINGA, 2004; LOBÃO; SILVA, 2013). A situação mais emblemática ocorre em Antas e Uauá, onde as terras antropizadas equivalem a mais de $90 \%$ da extensão municipal. A redução das feições vegetais no Polo Regional de Jeremoabo é uma situação que se generaliza em sete municípios, nos quais mais de $50 \%$ das terras são utilizadas para as lavouras e/ou pastagens.

Vê-se que as principais atividades econômicas regionais diminuíram, consideravelmente, a cobertura vegetal e decorreram em processos de resistasia. São forças motrizes que pressionam o ambiente para a formação de uma paisagem regional com cenários degradados, visualizados nas erosões, superfícies de solos pedregosas e proliferação de espécies pioneiras e ruderais.

Nimer (1988) indicou que o desmatamento está no cerne da desertificação ao desencadear uma série de fatores de degradação, como os de erosão acelerada que, conjugada à erosão laminar, rompe o estado de clímax, com impactos em todo o geossistema (potencial ecológico, exploração biológica e sociedade). Os problemas ambientais pioram com as práticas de queimadas, comumente utilizadas na preparação dos solos para as lavouras regionais (Figura 5). A repetição e intensidade das queimadas esgotam a capacidade de resiliência de parte das espécies vegetais, e sobrevivem, apenas, as arbustivas e arbóreas resistentes ao fogo e detentoras de mecanismos biológicos adaptativos, como a casca suberosa ou cortical (BRASIL, 2005). Destarte, as queimadas excessivas diminuem o estoque de sementes no solo que esperam a estação chuvosa para germinar (VASCONCELOS SOBRINHO, 1982). Este é um mecanismo 
de adaptação das espécies vegetais para enfrentar as estiagens pluviométricas, pois a planta não sobreviveria à falta de água no solo se as sementes brotassem imediatamente.

A pecuária e a agricultura são as principais atividades econômicas regionais e compõem elementos de pressão ambiental, por consequência das técnicas empregadas na reprodução dela. Foram - e permanecem - meios de ocupação dos sertões da Bahia e de degradação. O sobrepastoreio bovino e caprino associa-se à desertificação em distintas paisagens semiáridas. $\mathrm{O}$ pisoteio do gado pressiona a vegetação, ocorre na morte, a princípio, das espécies mais sensíveis das caatingas; ocasiona a compactação dos solos e um desequilíbrio no balanço da água no solo; retém a capacidade de infiltração, que constitui no efeito mais severo da degradação das terras secas; dificulta a germinação e desenvolvimento de plantas (WARREN; MAISELS, 1992). A quantidade demasiada de caprinos nas pastagens desencadeia diretamente processos de pressão ambiental pelo fato de as cabras se alimentarem das ervas próximas às superfícies dos solos e/ou juntas às raízes (WARREN; MAISELS, 1992), além de removerem materiais dos solos das vertentes. Esses fatos concorrem para a perturbação no equilíbrio ambiental e originam um estado de degradação, muitas vezes, difícil de resolver, como é o caso da desertificação.

Isso significa dizer que os efeitos da pecuária bovina e caprina nos processos de degradação dependem das práticas e dos sistemas de pastagens empregados. Nas terras do trópico semiárido, onde o manejo respeita a capacidade de suporte ambiental, certamente não haverá a ruptura do equilíbrio. A causa da degradação não deve recair, portanto, sobre os animais, e sim sobre a má gestão ambiental, sinalizada, muitas vezes, como ineficiente, ao avaliar as políticas governamentais no Brasil.

A identificação das classes de uso e cobertura da terra do Polo Regional de Jeremoabo possibilitou conceituar aspectos da vulnerabilidade ambiental à desertificação (Quadro 4), a partir das características da paisagem e dos fatores que geram pressão. Percebeu-se que existem feições específicas de áreas desertificadas, como aquelas encontradas na superfície erosiva flúvio-pluvial, correspondentes à erosão acelerada. Para cada classe, as políticas de enfrentamento ao processo de desertificação devem ser específicas e as pesquisas científicas podem apontar caminhos, como os encontrados no quadro 4. 
Quadro 4 - Aspectos conceituais da vulnerabilidade ambiental e respostas relacionadas às classes de uso e cobertura da terra - Polo Regional de Jeremoabo-BA

\begin{tabular}{|c|c|c|}
\hline Classe & Vulnerabilidade à desertificação & Recomendações \\
\hline $\begin{array}{l}\text { Caatinga } \\
\text { Arbóreo- } \\
\text { Arbustiva }\end{array}$ & $\begin{array}{l}\text { Baixa vulnerabilidade à desertificação. Há } \\
\text { biodiversidade vegetal, vegetação densa e } \\
\text { redução dos impactos da erosão }\end{array}$ & $\begin{array}{l}\text { Ampliação de unidades de conservação, } \\
\text { principalmente no sentido sudeste, onde } \\
\text { encontram-se feições vegetais conservadas }\end{array}$ \\
\hline $\begin{array}{l}\text { Caatinga } \\
\text { Arbóreo- } \\
\text { Arbustiva } \\
\text { Antropizada }\end{array}$ & $\begin{array}{l}\text { Vulnerabilidade moderada, tendendo a } \\
\text { intensificar-se em função da criação extensiva de } \\
\text { gado e da retirada de lenha, que reduz a cobertura } \\
\text { vegetal e expõe os solos às intempéries climáticas }\end{array}$ & $\begin{array}{l}\text { Acompanhamento técnicos, para indicar } \\
\text { alternativas de manejo, com respeito às } \\
\text { especificidades ambientais. Fiscalização } \\
\text { dos latifúndios na aplicação de leis, a fim de } \\
\text { coibir o desmatamento e o sobrepastoreio }\end{array}$ \\
\hline $\begin{array}{l}\text { Caatinga } \\
\text { Parque }\end{array}$ & $\begin{array}{l}\text { Medra em ambientes onde decorrem a baixa e } \\
\text { concentrada pluviosidade. Existe um } \\
\text { espaçamento natural das árvores e arbustos; os } \\
\text { solos, no tempo chuvoso, é recoberto pelo capim- } \\
\text { panasco (Aristida sp.) }\end{array}$ & $\begin{array}{l}\text { Escassez de estudos, por serem, } \\
\text { erroneamente, consideradas de baixa } \\
\text { biodiversidade. Importância das pesquisas } \\
\text { sobre a capacidade de adaptação das } \\
\text { espécies em ambientes com pluviosidade } \\
\text { inferior a } 400 \mathrm{~mm}\end{array}$ \\
\hline $\begin{array}{l}\text { Caatinga } \\
\text { Parque } \\
\text { Antropizada }\end{array}$ & $\begin{array}{l}\text { Espaçamento das árvores e arbustos e o capim- } \\
\text { panasco (Aristida sp.) favorecem desenvolver a } \\
\text { pecuária extensiva, que é um fator de pressão. A } \\
\text { vulnerabilidade se intensifica e configura cenários } \\
\text { de baixíssima resiliência ambiental, onde os } \\
\text { processos de desertificação se instalam }\end{array}$ & $\begin{array}{l}\text { Monitorar o uso, no intuito de diminuir a } \\
\text { pressão exercida pelas atividades } \\
\text { pecuaristas, que reduzem a capacidade de } \\
\text { rebrota do capim-panasco (Aristida sp.), } \\
\text { principal espécie que recobre os solos }\end{array}$ \\
\hline $\begin{array}{l}\text { Campo } \\
\text { Rupestre }\end{array}$ & $\begin{array}{l}\text { Ambientes frágeis, em razão da altitude e dos } \\
\text { afloramentos rochosos. Entretanto, a dificuldade } \\
\text { de acesso e as características dos solos } \\
\text { encontrados favorecem a preservação e/ou } \\
\text { conservação }\end{array}$ & $\begin{array}{l}\text { A diversidade de ambientes se traduz na } \\
\text { maior riqueza de espécies que necessitam } \\
\text { de estudos e de pesquisas. Existe a } \\
\text { importância de aplicar a legislação, para } \\
\text { efetivar o zoneamento ambiental e delimitar } \\
\text { as unidades de conservação }\end{array}$ \\
\hline $\begin{array}{l}\text { Lavoura e } \\
\text { Pastagem } \\
\text { Alternadas }\end{array}$ & $\begin{array}{l}\text { Alta vulnerabilidade ambiental, pois o uso } \\
\text { constante gera uma pressão ambiental, com a } \\
\text { culminância de solos expostos e erosão }\end{array}$ & $\begin{array}{l}\text { Utilização de técnicas de manejo que } \\
\text { valorizem a rotatividade agrícola, permita } \\
\text { o descanso, recuperação dos solos e demais } \\
\text { elementos ambientais }\end{array}$ \\
\hline $\begin{array}{l}\text { Lavoura } \\
\text { Irrigada }\end{array}$ & $\begin{array}{l}\text { As práticas de irrigação, geralmente realizadas } \\
\text { por aspersores, não condizem com as } \\
\text { especificidades ambientais, decorrem na } \\
\text { salinização dos solos, na erosão, introdução de } \\
\text { espécies alóctones, acentuação das desigualdades } \\
\text { sociais (acesso à irrigação das elites locais) e em } \\
\text { outros problemas relacionados à desertificação }\end{array}$ & $\begin{array}{l}\text { Aplicar as políticas ambientais engendradas } \\
\text { nas instituições governamentais, } \\
\text { relacionadas ao uso correto das técnicas e } \\
\text { tecnologias de convivência com a seca }\end{array}$ \\
\hline Pastagem & $\begin{array}{l}\text { Alta vulnerabilidade à desertificação decorrente } \\
\text { dos impactos do pisoteio permanente do gado, da } \\
\text { supressão total da vegetação, remoção dos } \\
\text { sedimentos superficiais pedológicos, exposição } \\
\text { dos solos às intempéries, com acentuação da } \\
\text { erosão }\end{array}$ & $\begin{array}{l}\text { Identificar tecnologias adequadas para o } \\
\text { manejo e convívio em ambientes } \\
\text { semiáridos. Associar pesquisas científicas e } \\
\text { conhecimentos das comunidades locais, } \\
\text { para efetivar a sustentabilidade }\end{array}$ \\
\hline $\begin{array}{l}\text { Solo } \\
\text { Exposto }\end{array}$ & $\begin{array}{l}\text { Extrema vulnerabilidade à desertificação devido à } \\
\text { supressão da cobertura vegetal e da exposição das } \\
\text { terras às intempéries climáticas, com a ocorrência } \\
\text { de processos erosivos e alta taxa de evaporação da } \\
\text { água no solo }\end{array}$ & $\begin{array}{l}\text { Realizar estudos para a recomposição } \\
\text { dessas áreas com a utilização de espécies } \\
\text { nativas locais }\end{array}$ \\
\hline $\begin{array}{l}\text { Superfície } \\
\text { Erosiva } \\
\text { Flúvio- } \\
\text { Pluvial }\end{array}$ & $\begin{array}{l}\text { Severa vulnerabilidade à desertificação, em } \\
\text { virtude da retirada da mata ciliar e formação de } \\
\text { ravinas e voçorocas. As feições já indicam um } \\
\text { estado de degradação decorrente do } \\
\text { pressionamento das atividades pecuaristas }\end{array}$ & $\begin{array}{l}\text { Demarcação de APP, a partir da aplicação } \\
\text { da legislação ambiental, para recomposição } \\
\text { da mata ciliar e manutenção da relativa } \\
\text { umidade dos solos em ambientes de rios, } \\
\text { como os intermitentes }\end{array}$ \\
\hline
\end{tabular}

Fonte: Autores (2020) 
No Polo Regional de Jeremoabo, encontram-se ambientes preservados, onde a aplicação das leis ambientais vigentes poderá conduzir a um zoneamento ambiental, ampliar as unidades de conservação e ser medidas eficazes de combate ao processo de desertificação (Quadro 4). Uma rede de fatores está envolvida no desencadeamento da degradação das terras secas e repensar nas técnicas e práticas de uso pode direcionar para o manejo das terras e gerar um estado de sustentabilidade ambiental.

\section{CONSIDERAÇÕES FINAIS}

No estudo referente ao processo de desertificação, a aplicação de indicadores ambientais é importante para gerar dados e informação para a análise ambiental. $\mathrm{O}$ indicador uso e ocupação da terra, mediante o mapeamento, possibilitou averiguar fatores de desertificação no contexto do Polo Regional de Jeremoabo.

As evidências da degradação ambiental se principiaram na pressão sobre a biomassa, que torna os solos friáveis e de horizontes superficiais arenosos e/ou pedregosos suscetíveis às intempéries climáticas para o rompimento do equilíbrio dinâmico paisagístico. $\mathrm{O}$ mapeamento de uso e cobertura das terras denotou a agropecuária como fator da supressão das feições vegetais em favor da ampliação dos campos de agricultura e pecuária. Essas áreas se estenderam por diferentes espaços regionais, totalizaram 12,4 mil km², e demonstraram estados de deterioração da vegetação e do ambiente, que se manifestaram na (re)classificação das feições vegetais, com o qualitativo antropizada, no intuito de indicar as interferências humanas na biodiversidade vegetal.

A intensa exploração do ambiente configurou situações preocupantes em diferentes espaços, com a ampliação das terras antropizadas, sobretudo em Antas e Uauá, onde elas equivaleram a mais de $90 \%$ da extensão municipal. A redução das feições vegetais no Polo Regional de Jeremoabo é uma situação que se generaliza em sete municípios, nos quais mais de $50 \%$ das terras são utilizadas para as lavouras e/ou pastagens. Há aqueles em que as terras somam mais de $1.000 \mathrm{~km}^{2}$ nessa situação, como em Canudos, Chorrochó, Jeremoabo e Uauá.

O solo exposto distribuiu-se em diferentes áreas, sobretudo, nos municípios de Chorrochó, Macururé, Paulo Afonso e Uauá. A superfície erosiva flúvio-pluvial se prolongou em 1,2 mil km² do Polo Regional de Jeremoabo, nas margens de diferentes rios, onde os processos erosivos são atuantes e as feições vegetais são inexistentes. Ambas as classes, de solo 
exposto e de superfície erosiva flúvio-pluvial, indicaram o rompimento do estado de equilíbrio climáxico entre o potencial ecológico, exploração biológica e as ações antrópicas.

Pelo mapeamento de uso e cobertura da terra, constatou-se, ainda, as extensas áreas desprovidas de cobertura vegetal nos municípios de Antas, Coronel João Sá, Novo Triunfo e Pedro Alexandre; a supressão da vegetação natural em mais de $81 \%$ das terras de Antas, Coronel João Sá, Pedro Alexandre e Uauá; e, em compensação, a existência, em torno de 13,4 mil km², de terra recoberta por feições vegetais, que apontou para a conservação e preservação das paisagens, sobretudo, de áreas municipais de Canudos, Chorrochó, Jeremoabo, Macururé e Rodelas - pela extensão das classes vegetais.

No contexto desse estudo, o uso e cobertura da terra possibilitou indicar as áreas de alta vulnerabilidade à desertificação, associadas aos fatores de pressão. Essas informações são importantes para subsidiar políticas de enfrentamento à degradação das terras secas, que assolam o ambiente, por causar impactos nas dimensões físicas, biológicas e sociais. Ademais, este estudo demonstrou ambientes conservados, com possibilidades de associar a outros dados para delinear ações que conduzem a manutenção do equilíbrio ambiental, como a ampliação de unidades de conservação já existentes no Polo Regional de Jeremoabo.

\section{AGRADECIMENTOS}

À Fundação de Amparo à Pesquisa da Bahia (FAPESB), pelo apoio financeiro e concessão de bolsas.

\section{REFERÊNCIAS}

AB'SABER, A. N. Problemática da desertificação e da savanização no Brasil intertropical. Geomorfologia, São Paulo, n. 53, p. 1-19, 1977.

AJAJ, Q. M.; PRADHAN, B.; NOORI, A. M.; JEBUR, M. N. Spatial monitoring of desertification extent in western Iraq using LANDSAT images and GIS. Land Degradation e Development, [s.1], n. 28, n. 8, p. 2418-2431, 2017. DOI: 10.1002/ldr.2775

ANDRADE, J. B.; OLIVEIRA, T. S. Análise espaço-temporal do uso da terra em parte do semiárido cearense. Revista Brasileira de Ciência do Solo, v. 28, n. 2, p. 393-401, 2004. DOI: 10.1590/S0100-06832004000200018.

AQUINO, C. M. S.; ALMEIDA, J. A. P.; OLIVEIRA, J. G. B. Estudo da cobertura vegetal/uso da terra nos anos de 1987 e 2007 no núcleo de degradação/desertificação de São Raimundo Nonato - Piauí. RA'EGA, Curitiba, n. 25, p. 252-278, 2012. DOI: http://dx.doi.org/10.5380/raega.v25i0.28013.

BAHIA. Plano estadual de combate à desertificação e mitigação dos efeitos da seca PAE/BA. Salvador: INEMA, 2014. 
BRASIL. Programa nacional de combate à desertificação e mitigação dos efeitos da seca - PAN-Brasil. Brasília, DF: Ministério do Meio Ambiente; Secretaria de Recursos Hídricos, 2005.

CHEN, W.; WANG, Y.; LI, W. LIAO, Y. YANG, J. Land use/land cover change and driving effects of water environment system in Dunhuang Basin, northwestern China. Environmental Earth Sciences, [s.1], n. 75, p. 1-11, 2006. DOI: 10.1007/s12665-016-5809-9.

CONSELHO NACIONAL DA RESERVA DA BIOSFERA DA CAATINGA. Cenários para o bioma caatinga. Recife: Secretaria da Ciência, Tecnologia e Meio Ambiente, 2004.

DRONOVA, I.; GONG, P.; CLINTON, N.E.; WANG, L.; FU, W.; QI, S.; LIU, Y. Landscape analysis of wetland plant functional types: the effects of image segmentation scale, vegetation classes and classification methods. Remote Sensing of Environment, [s.1], v. 127, p. 357-369, 2012. DOI: 10.1016/j.rse.2012.09.018.

ESTOQUE, R. C.; MURAYAMA, Y. Classification and change detection of built-up lands from Landsat-7 ETM+ and Landsat-8 OLI/TIRS imageries: A comparative assessment of various spectral indices. Ecological Indicators, [s.1], v. 56, p. 205-217, 2015. DOI: 10.1016/j.ecolind.2015.03.037.

FLORENZANO, T. G. Sensoriamento remoto para geomorfologia. In: FLORENZANO, T. G. (Org.). Geomorfologia: conceitos e tecnologias atuais. São Paulo: Oficina de Textos, 2008.

HARE, F. K et al. Desertificação: causas e consequências. Lisboa: Fundação Calouste Gulbenkian, 1992.

INSTITUTO BRASILEIRO DE GEOGRAFIA E ESTATÍSTICA (IBGE). Manual técnico da vegetação brasileira. Rio de Janeiro: IBGE, 1992.

. Manual técnico da vegetação brasileira. 2. ed. Rio de Janeiro: IBGE, 2012.

. Manual técnico de uso da terra. 2. ed. Rio de janeiro; IBGE, 2006.

. Manual técnico de uso da terra. 3. ed. Rio de Janeiro: IBGE, 2013.

JENSEN, J. R. Sensoriamento remoto do ambiente. São José dos Campos: Parêntese, 2009.

LOBÃO, J. S. B.; SILVA, B. C. N. Análise socioambiental na região semiárida da Bahia: geoprocessamento como subsídio ao ordenamento territorial. Feira de Santana: UEFS, 2013.

LOBÃO, J. S. B.; VALE, R. M. C. Lógica fuzzy na modelagem da desertificação no estado da Bahia. Geografia, Rio Claro, v. 38, n. 1, p. 123-140, 2013.

MAINGUET, M. L'Homme et la sécheresse. Paris: Masson, 1995.

MIRANDA, J. D.; PADILLA, F. M.; PUGNAIRE, F. I. Sucesión y restauración en ambientes semiáridos. Ecosistemas, Madrid, v. 13, n. 1, p, 55-58, 2004.

NASCIMENTO, F. R. O fenômeno da desertificação. Goiânia: UFG, 2013.

NIMER. E. Desertificação: realidade ou mito? Revista Brasileira de Geografia, Rio de Janeiro, v. 50, n.1, p.7-39, 1988.

OLIVEIRA JUNIOR, I.; LOBÃO, J. S. B.; SILVA, B. C. N.; PEREIRA, A. J. Indicadores socioeconômicos de desertificação: a análise da produção agropecuária no polo regional de Jeremoabo - Bahia. Geonordeste, São Cristovão, v. 29, n. 2, p. 23-42, 2018. 
PACHÊCO, A. P.; FREIRE, N. C. F.; BORGES, U. N. A Trandisciplinaridade da desertificação. Geografia, Londrina, v. 15, n. 1, p. 5-34, 2006. DOI: http://dx.doi.org/10.5433/2447-1747.2006v15n1p5

PAES, M. L. N.; DIAS, I. F. O. Plano de manejo: Estação Ecológica Raso da Catarina. Brasília, DF: Ibama, 2008.

PONZONI, F. J. Sensoriamento remoto no estudo da vegetação. São José dos Campos: Parêntese, 2009.

RIBEIRO, K. V.; ALBUQUERQUE. E, L. S. Mapeamento das Formas de Uso e Cobertura da Terra na Bacia Hidrográfica do Rio Mulato, Estado do Piaú. Caderno de Geografia, Velo horizonte, v. 27, n. especial, p. 106-118, 2017. DOI: DOI 10.5752/p.2318-2962.2017v27 nesp1p106.

RUDORFF, B. F. T.; SHIMABUKURO, Y. E.; CEBALlOS, J. C. O sensor MODIS e suas aplicações ambientais no Brasil. São José dos Campos: Parênteses, 2007.

SALES, M. C. L. Evolução dos estudos de desertificação no Nordeste Brasileiro. GEOUSp: Espaço e Tempo, São Paulo, n. 11, p. 115-116, 2002. DOI: https://doi.org/10.11606/issn.21790892.geousp.2002.123650.

SALES, M. C. L. Degradação ambiental em Gilbués, Piauí. Mercator, Fortaleza, v. 2, n. 4, p. 115-124, 2003. DOI: 10.4215/RM0000.0000.0000.

SOUZA, B. I.; SUERTEGARAY, D. M. A.; LIMA, E. R. V. Desertificação e seus efeitos na vegetação e solos do Cariri Paraibano. Mercator, Fortaleza, v. 8, n. 16, p. 217-232, 2009. DOI: 10.4215/RM2009.0816.0017.

SUERTEGARAY, D. M. A. Desertificação: recuperação e desenvolvimento sustentável. In: GUERRA, J. T.; CUNHA, S. B. Geomorfologia e meio ambiente. 9. ed. Rio de Janeiro: Bertrand Brasil, 2010.

SUPERINTENDÊNCIA DE ESTUDOS ECONÔMICOS E SOCIAIS DA BAHIA - SEI. Balanço hídrico do estado da Bahia. Salvador: SEI, 1999.

UNITED NATIONS. Elaboration of an international convention to combat desertification in countries experiencing serious drought and/or desertification, particularly in Africa. New York: United Nations, 1994.

VASCONCELOS SOBRINHO, J. Núcleos de desertificação no polígono das secas. In: ICB, 1. 1971, Recife. Anais... Recife: Universidade Federal de Pernambuco, 1971.

Processos de desertificação ocorrentes no nordeste do Brasil: sua gênese e sua contenção. Recife: SEMA/SUDENE, 1982.

Desertificação no Nordeste do Brasil. Recife: Fundação Apolônio Salles de Desenvolvimento Educacional-Fadurpe. Universidade Federal Rural de Pernambuco, 2002.

WARREN, A.; MAIZELS, J. K. Mudança ecológica e desertificação. In: HARE, F. K et al. Desertificação: causas e consequências. Lisboa: Fundação Calouste Gulbenkian, 1992. 